\title{
Prompt and Delayed Fluorescences
}

\author{
Korkut Yegin, ${ }^{1}$ Ş. İpek Karaaslan, ${ }^{2}$ and Necdet Aslan ${ }^{2}$ \\ ${ }^{1}$ Department of Electrical and Electronics Engineering, Yeditepe University, 34755 Istanbul, Turkey \\ ${ }^{2}$ Physics Department, Yeditepe University, 34755 Istanbul, Turkey
}

Correspondence should be addressed to Korkut Yegin, kyegin@yeditepe.edu.tr

Received 6 December 2012; Accepted 6 December 2012

Copyright (C) 2012 Korkut Yegin et al. This is an open access article distributed under the Creative Commons Attribution License, which permits unrestricted use, distribution, and reproduction in any medium, provided the original work is properly cited.

The photophysical and chemical behaviors of certain materials manifest themselves in the form of prompt and delayed fluorescence. This issue compiles eight exciting manuscripts on prompt and delayed fluorescence with broad range of applications.

Acoustic cavitation of gold nanoparticles in acid solutions by spectrofluorometry method was explored in detail by A. Sezegania et al. They show that Acoustic cavitation in the presence of gold nanoparticles provides a new way for improving therapeutic effects on the tumors in sonodynamic therapy.

Structural configuration of mylein figures using fluorescence micrsocopy was shown in this special issue by L. Tayebi et al. Employing epiflouerescent microscopy, they studied the lifetime and configuration of myelin figures in experiment of lipid hydration. They found direct correlations between the lifetime of myelin figures and the experimental conditions such as temperature, density of the parent stack, and the hydrophobicity of the substrate.

Microwave irradiation effects on the electronic structure of cresyl violet in solution was studied by F. Bayrakceken et al. These changes are important because Cresyl violet is often used as a staining agent for studying changes on DNA and RNA-rich compounds in tissues. Based on absorption spectra, they concluded that cresyl violet molecular structure due to the microwave irradiation was changed and the phononic product could not be used as a laser-dye after microwave irradiation.

In another study by F. Bayrakceken et al. discrete absorption and resonance coherent fluorescence line of silicon dioxide were recorded photographically and discrete fluorescence was observed at room temperature using high photon flux excitation spectroscopy. They state that it is possible to use fused silica as a laser material in the UV or as a UV detector with its inherit visible-blind property.

$\mathrm{H}$. Ozturk and his colleagues showed that the inversion of ammonia molecule which results in split rotational spectral lines can be used to detect presence of ammonia in water for counter bioterrorism applications. Millimeter wave absorption using a coherent source and detector was used to provide experimental evidence.

F. Bayrakceken et al. analyzed polycyclic aromatic hydrocarbon compound, 1,2:3,4-dibenzanthracene spectroscopically in ethanol. Ultraviolet absorption spectra and fluorescence measurements were performed to show that Stokes' lines were discernible. Being a carcinogenic compound, the detection of 1,2:3,4-dibenzanthracene presence in environment as a pollutant is crucial in many applications.

M. A. Yesil studied millimeter wave absorption of $\mathrm{TiO}_{2}$ nanoparticles deposited on glass assembly. Absorption of millimeter waves by a thin film of $\mathrm{TiO}_{2}$ nanoparticles at distinctive frequency band was shown with a network analyzer.

Optical energy transfer at room temperature plays an important role in many applications. Electronically excited naphthalene with 200-260 nm ultraviolet (UV) light emits photons in its emission band and the emitted photons are absorbed by biacetyl, and then, excited biacetyl phosphorescence. The resulting phosphorescence was shown to be very stable with emission peak at $545 \mathrm{~nm}$ for different excitation wavelengths from 200 to $260 \mathrm{~nm}$. Similar optical energy transfer was shown from pyrazine to biacetyl. Optical energy transfer mechanisms were detailed.

By compiling this special issue, we hope to enrich our readers and researchers understanding and broad applications of prompt and delayed fluorescence. 


\section{Acknowledgment}

We also pay special tribute to Professor Fuat Bayrakceken, an inspirational scientist, whom we lost unexpectedly during the preparation of this special issue. Professor Bayrakceken was mostly known with his discovery of a new fluorescence type known as B-type fluorescence.

Korkut Yegin Ş. İpek Karaaslan Necdet Aslan 


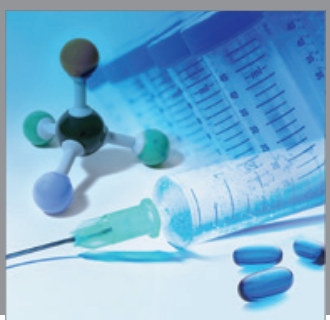

International Journal of

Medicinal Chemistry

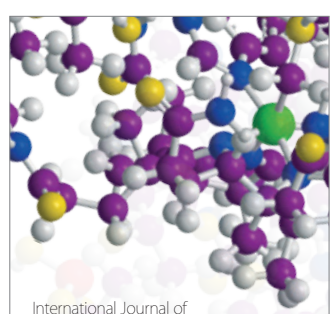

Carbohydrate Chemistry

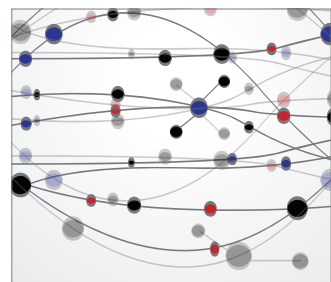

The Scientific World Journal
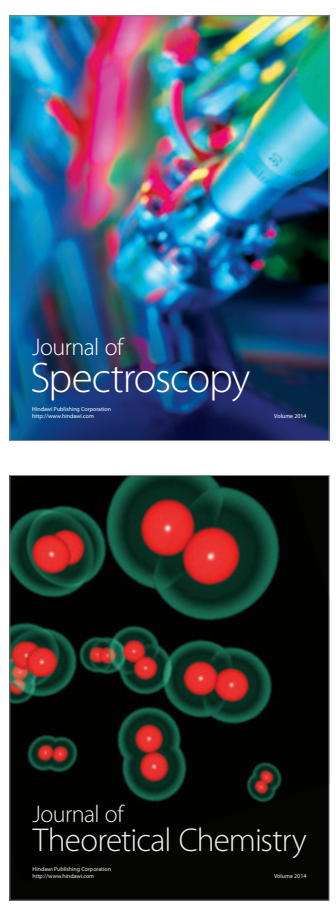
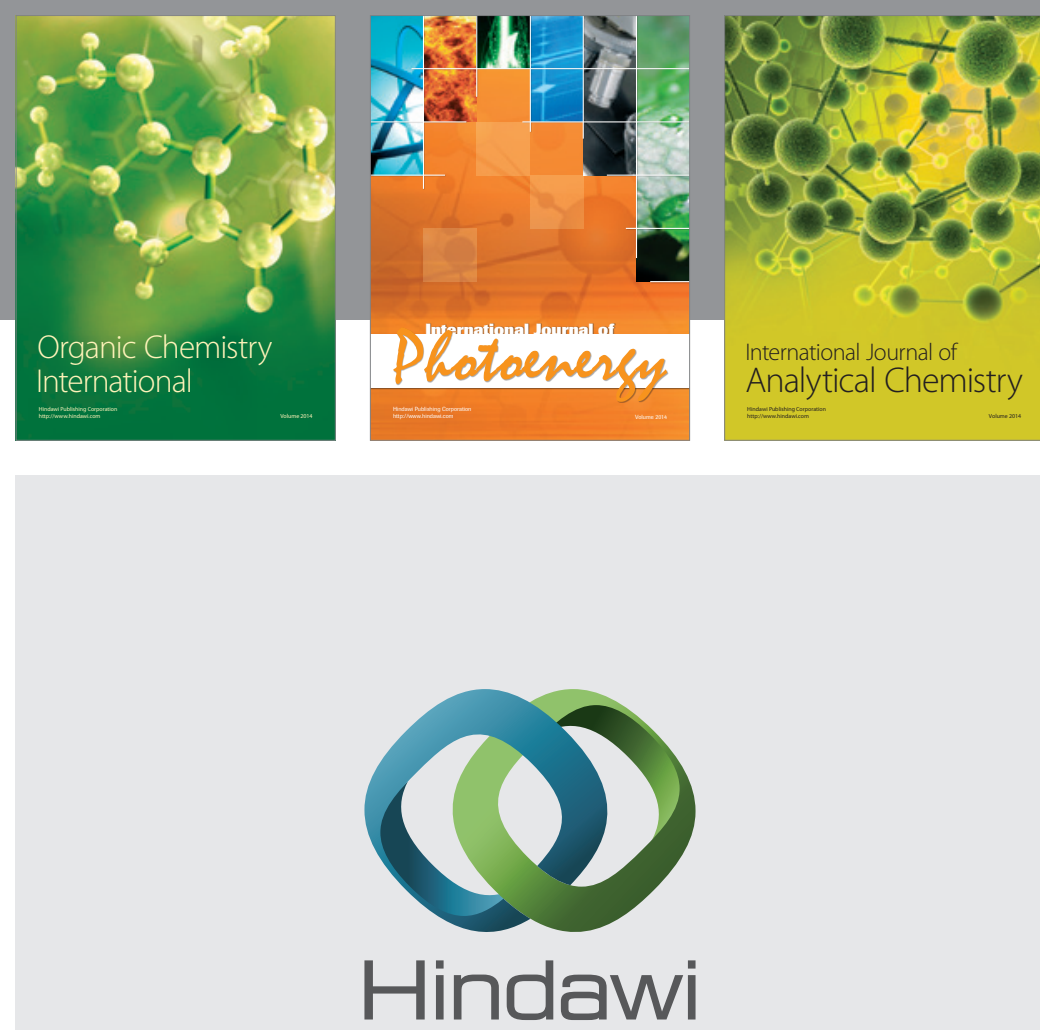

Submit your manuscripts at

http://www.hindawi.com
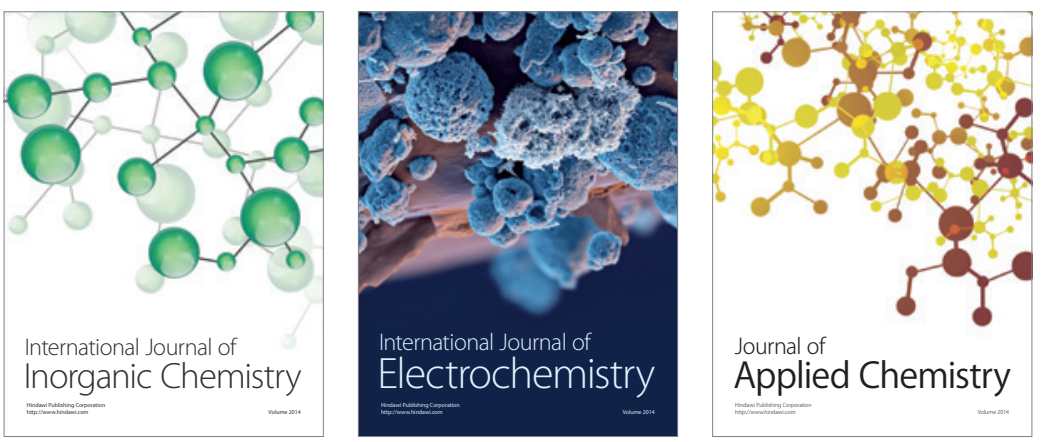

Journal of

Applied Chemistry
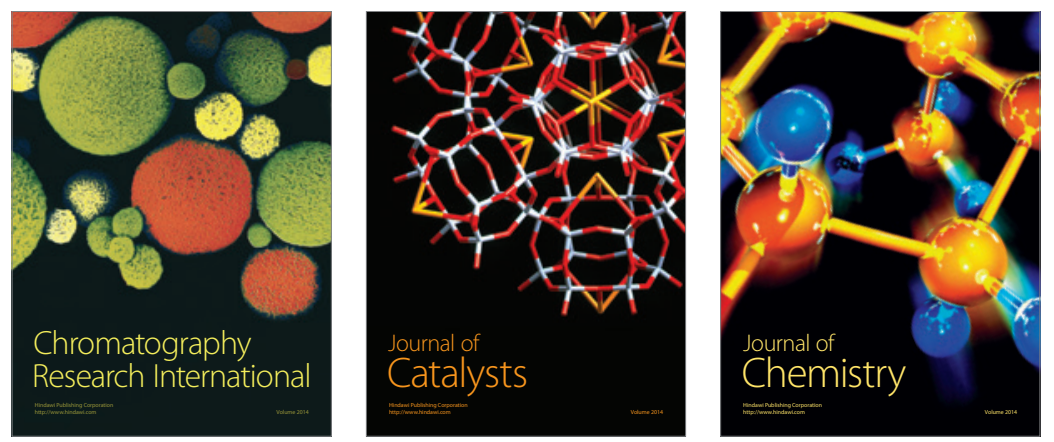
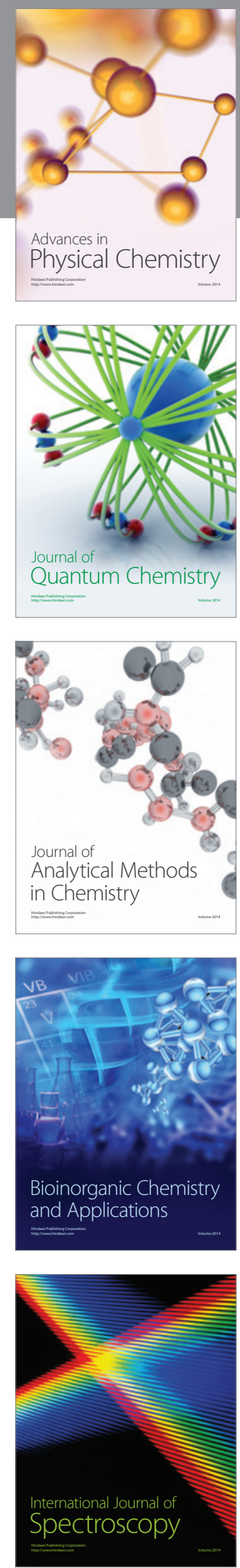